\title{
Lo sagrado en Mircea Eliade
}

The Sacred in Mircea Eliade

\author{
LUCAS RISOTO DE MESA
}

Universidad de Málaga (España)

\begin{abstract}
RESUMEN
Este trabajo pretende ser una exposición de los conceptos fundamentales de Eliade y de cómo se articulan entre sí. En primer lugar, hablaremos de su concepto más importante: lo sagrado. En segundo lugar, hablaremos de la fundación del mundo que permite el descubrimiento de lo sagrado por el hombre primitivo. En tercer lugar, trataremos la cuestión de la repetición que es lo sagrado en el tiempo. Esto obliga a hablar de las dos grandes concepciones del tiempo: la concepción cíclica y la concepción del tiempo lineal. Por último, hablaremos del olvido de lo sagrado en las sociedades occidentales modernas.

PALABRAS CLAVE

LO SAGRADO, LA FUNDACIÓN DEL MUNDO, LA REPETICIÓN, CONCEPCIÓN CÍCLICA Y LINEAL DEL TIEMPO, OLVIDO DE LO SAGRADO
\end{abstract}

\begin{abstract}
This paper is an exposition of the main concepts of Mircea Eliade and how they articulate between them. Firstly, we will talk about his most important concept: the sacred. Secondly, we will talk about the foundation of the world that allow the foundation of the sacred by the primitive man. Thirdly, we will deal with the concept of repetition defined as the sacred in time. Then, we will have to speak about the two big conceptions of time: the cyclical conception and the linear conception. Last, we will speak about the forgetfulness of the sacred in modern society.
\end{abstract}

Claridades. Revista de filosofía, 6 (2014), pp. 33-48.

ISSN: 1889-6855 ISSN-e: 1989-3787 Dl.: PM 1131-2009

Asociación para la promoción de la Filosofía y la Cultura (FICUM) 


\author{
KEY WORDS \\ THE SACRED, THE FOUDATION OF THE WORLD, \\ REPETITION, CYCLICAL CONCEPTION OF TIME, LINEAR \\ CONCEPTION OF TIME, FORGETFULNESS OF SACRED
}

\title{
I. INTRODUCCIÓN
}

LA OBRA DE MirCEA Eliade (1907-1986) SE ENMARCA en la historia de las religiones y la etnología. Presenta sin embargo, un enorme interés para la filosofía en la medida en que ayuda a plantear ciertas cuestiones de una manera completamente nueva que no permite, por ejemplo, el estudio de historia de la filosofía más ortodoxa. La metafísica occidental aparece a una luz completamente nueva si se examina teniendo como fondo la totalidad del pensamiento humano. Hay que tener en cuenta, que la historia de la filosofía en Occidente tiene escasos 2500 años, mientras que la especie humana tiene 2,5 millones de años si tomamos el paleolítico como referencia. Muy a menudo, el error del filósofo consiste en infravalorar la importancia del mito, del que la humanidad vivió millones de años. El logos, traducido como razón, habría triunfado sobre el mito, liberando a la humanidad de un largo periodo de tinieblas. Pero es absurdo suponer que la humanidad haya permanecido en la oscuridad durante milenios. Más bien tenemos que entender que el pensar religioso contenido en los mitos tiene unos caracteres propios que han sido útiles al ser humano y que se contraponen al pensar basado en el logos. Desentrañar estos caracteres propios es tarea difícil dado que los mitos arraigan en una cultura oral que se ha perdido por completo. Por eso, el objeto de estudio de la etnología son las sociedades primitivas o arcaicas que son aquellas que no han desarrollado todavía la escritura y por lo tanto no han entrado en la historia.

Esta es la tarea que realiza Mircea Eliade. Este trabajo pretende ser una exposición de los conceptos fundamentales de Eliade y de cómo se articulan entre sí. En primer lugar, hablaremos de su concepto más importante: lo sagrado. En segundo lugar, hablaremos de la fundación del mundo que permite el descubrimiento de lo sagrado por el hombre primitivo. En tercer lugar, trataremos la cuestión de la repetición que es lo sagrado en el tiempo. Esto obliga a hablar de las dos grandes concepciones del tiempo: la concepción cíclica y la concepción del tiempo lineal. Por último, hablaremos del olvido de lo sagrado en las sociedades occidentales modernas. 


\section{EL CONCEPTO DE LO SAGRADO}

La historia de las religiones consiste en una acumulación de hierofanías. Una hierofanía es la manifestación de lo sagrado en la naturaleza. El hombre primitivo entiende que la naturaleza puede actuar de receptáculo de lo trascendente y al mismo tiempo continuar siendo naturaleza. Una piedra, un árbol, una montaña pueden ser simultáneamente naturales y sagrados, es decir, pueden albergar lo completamente otro (ganz andere) en su forma natural. Así puede constatarse por ejemplo en el episodio de la Biblia en que Dios se revela a Moisés a través de una zarza ardiendo. Encontramos hierofanías en las visiones de los profetas, en la mayoría de los mitos de las sociedades arcaicas, o en la encarnación de Dios en Cristo. En cierto modo, cuando la divinidad se manifiesta en lo meramente natural, ésta acepta limitarse, lo cual constituye la paradoja del misterio de lo sagrado.

Las sociedades primitivas articulan una ontología de acuerdo con la oposición sagrado-profano. ¿Qué es lo sagrado? Lo sagrado es lo que está saturado de ser, de realidad, de potencia o de fuerza. Lo profano es aquello que está más o menos afectado de irrealidad o de pobreza ontológica. El hombre primitivo toma como referencia lo sagrado para discernir lo real de lo irreal. Es por ello, a diferencia del moderno, un homo religiosus, un hombre que se esfuerza por mantenerse en la cercanía de la divinidad para orientarse en el mundo. "El deseo del hombre primitivo de vivir en lo sagrado equivale, de hecho, a su afán de situarse en la realidad objetiva, de no dejarse paralizar por la realidad sin fin de experiencias puramente subjetivas, de vivir en un mundo real y eficiente y no en una ilusión"1. La experiencia de lo sagrado no pertenece al plano puramente subjetivo o psicológico sino a lo estrictamente objetivo, es la roca firme desde donde poder orientarse en el mundo. Lo profano solo existe porque participa de alguna manera en lo sagrado. Se trata a fin de cuentas, de dos modos de estar en el mundo, los dos modos del homo religiosus primitivo.

Mircea Eliade traduce de forma aproximada a un lenguaje comprensible para nosotros todo lo referente a las sociedades primitivas. Ellas no disponen de nuestra terminología filosófica occidental, pero se encuentra el concepto de "la cosa" para referirse a lo sagrado. Sin embargo, lo sa-

1 M. ELIADE. Mitos, sueños y misterios. Madrid: Grupo Libro 88. p. 31.

Claridades. Revista de Filosofía, 6 (2014) 
grado incluye para el primitivo, no solo lo real por excelencia sino también "lo fuerte", "lo efectivo". "Para la conciencia de los pueblos arcaicos, "lo fuerte", lo sagrado es una expresión de la realidad por excelencia". Así, Eliade llega a la fórmula "toda hierofanía es una kratofanía". Lo sagrado es fuente de poder. "Poder quiere decir a la vez realidad, perennidad y eficacia." ${ }^{4}$ En último término da la impresión de que para los pueblos primitivos no existe una separación neta entre poder y ser. Ambos son dos aspectos de lo sagrado. Esto se pone en evidencia en la creencia de los melanesios en el mana, una fuerza impersonal y universal intitulada. El mana se manifiesta en la fuerza corporal pero también en toda fuerza poseída por el hombre. Cualquier objeto puede ser portador del mana y cualquiera puede comunicarlo. El hombre lo obtiene de seres más poderosos que él como los espíritus o dioses. La divinidad crea el universo por un exceso de mana, el jefe de la tribu dispone de una cantidad especial de él, de igual forma puede decirse que "una embarcación no es rápida más que cuando posee mana, tanto como una red que recoge peces o una flecha que hiere mortalmente." ${ }^{5} \mathrm{El}$ mana es el poder de que está investido un objeto, lo que vuelve a un recurso efectivo. Ian Hogbin comenta sobre estas tribus primtivas "un hombre podrá trabajar duramente, pero jamás llegará a ser rico como no obtenga que los espíritus lo aprueben y ejerzan su poder en favor suyo." ${ }^{6}$

Lo sagrado entendido como una fuente de poder tiene una estructura ambivalente. Por un lado atrae y por otro repele. Eliade comenta la frase de Virgilio "auri sacra fames" en donde "sacra" significa a un tiempo "maldito" y "santo". Lo sagrado puede ser también lo que tiene mácula. Los objetos maculados están prohibidos a la experiencia profana. Es necesaria una preparación ritual tanto para tomar contacto con lo maculado como para alejarse de él. Lo maculado es tabú. "Lo que - con una palabra polinesia adoptada por los etnólogos- se llama tabú es precisamente esa condición de los objetos, de las acciones o de las personas "aisladas" y "prohibidas" por el peligro que su contacto lleva consigo."

2 Ibid., p.139.

3 Del griego kratos (fuerza).

4 Ibid., p.139.

5 Ibid., p.135.

6 Ibid., p.135.

7 M. ELIADE (1964) Tratado de historia de las religiones. Madrid: Ediciones Cristiandad. 1974. p.39. 
Los tabúes pueden ser provisionales como la mujer, el muerto o el enfermo. Se explican por una concentración de fuerzas en un determinado lugar. Hay otros tabúes permanentes como el tabú del rey. Está prohibido tocarle, acercarse a él, no se le puede mirar directamente o dirigirle la palabra sin antes haber tomado una serie de precauciones.

La ambivalencia de lo sagrado está originada por un lado por el deseo de incrementar la propia realidad y poder mediante el contacto directo de la hierofanía y por otro por el temor de perder la propia realidad por una cercanía excesiva de lo sagrado.

\section{LA FUNDACIÓN DEL MUNDO}

La hierofanía es una irrupción de lo sagrado en el mundo. Es aquello que crea un espacio heterogéneo. De un lado, situado en la cercanía del foco de lo sagrado, el espacio habitable de la ciudad, la aldea, la polis o el poblado. De otro lado, a medida que nos alejamos de lo sagrado se abre lo inhóspito. El espacio habitable solo aparece tras la consagración de un territorio mediante la repetición ritual de la cosmogonía. Cuando los primeros colonos escandinavos llegaron a Islandia su primera tarea fue la consagración del territorio. Trabajando la tierra, los colonos repetían el acto de creación primordial por el cual los dioses transformaron la tierra áspera y helada en un terreno habitable. La manifestación de lo sagrado transforma el caos de una región en un cosmos habitable. El trabajo del hombre que permite que de las masas amorfas surja una forma reconocible es la repetición del acto creador de los dioses. La repetición de la cosmogonía cosmiza $a^{8}$ el territorio delimitándolo del caos exterior. Esta delimitación traduce la ambivalencia originaria de lo sagrado según una oposición interior-exterior. En el interior, la santidad de lo sagrado irradia sobre las formas surgidas del trabajo humano. Hacia el exterior se abre lo informe, lo siniestro. Es el otro mundo donde habitan las larvas, los demonios, los enemigos o los extranjeros. Es curioso hacer notar que las primeras defensas que los primitivos instalaron en el límite de sus aldeas fueron defensas mágicas («estas defensas -fosos, laberintos, murallas- estaban destinadas más bien para impedir la invasión de los demonios y las almas de los muertos que para rechazar el ataque de los humanos» ${ }^{9}$. Con ellas se pretendía conjurar a los demonios para que retroce-

8 Neologismo creado por Eliade.

9 M. ELIADE. Mitos, op. cit.,p. 30.

Claridades. Revista de Filosofía, 6 (2014) 
dieran a su mundo informe. En ocasiones la consagración de un territorio representaba la victoria de un dios contra un monstruo originario. Tal era el caso, por ejemplo, de Marduk en la mitología babilónica y su victoria sobre Tiamat. El temor de la invasión del enemigo era el temor a la derrota del dios en su lucha contra el monstruo, o en otros términos, era el temor a la irrupción del caos en el territorio cosmizado de la cuidad. El hombre primitivo, al repetir la cosmogonía en una zona no solamente establece una oposición horizontal interior-exterior, cercanía-lejanía, sino también una vertical: las alturas, las profundides. El lugar de la hierofanía es donde se ponen en conexión los tres niveles cósmicos: el cielo, la tierra y el infierno. Es posible ascender a los cielos a través del axis mundi, la columna universal que vertebra el mundo. El axis mundi, se encuentra en el centro de toda la creación, y puede ser un pilar, una escalera, una montaña, un árbol... El chamán altaico realiza la ascensión a los Cielos en un estado de trance a través del Árbol Cósmico, un álamo que está situado en el centro del mundo. Entre los buriatos, la ceremonia iniciática para convertirse en chamán consiste en ascender hasta los cielos por un álamo situado en el interior de una morada subterránea. En el origen de los tiempos los dioses bajaban de los cielos y se mezclaban con la gente. Los hombres, por su parte podían ascender fácilmente hasta los cielos. En la actualidad, (en muchos mitos, después de un suceso traumático) se ha vuelto casi imposible, y solo los chamanes pueden realizarla.

El territorio consagrado está siempre en el centro del mundo. Desde este centro se extienden los cuatro puntos cardinales. El mundus romano era una fosa circular dividida en cuatro. Era tanto la imagen del cosmos como el modelo de un mundo habitable. «El mundus se asimila evidentemente al omphalos, al ombligo de la tierra: la Ciudad (orbs) se situaba en medio del orbis terrarum». ${ }^{10} \mathrm{La}$ instalación en un territorio equivale también a fundación de un mundo. Solo desde el centro del mundo es posible la orientatio, la orientación. Pero un territorio solo llega a ser el centro del mundo porque desde él es posible la comunicación con lo trascendente. Sin embargo, encontramos aquí una cuestión paradójica dado que una buena parte de mitos y de ritos nos hablan de la dificultad de llegar a un centro, por ejemplo, el viaje de Ulises a Ítaca o la peregrinación a Tierra Santa. El camino que lleva al centro es difícil y está sembrado de obstáculos. Se habita en el centro, pero éste también se halla lejos. El

10 M. ELIADE (1957) Lo sagrado y lo profano. Barcelona: Editorial Labor.1994. p.46.

Claridades. Revista de Filosofía, 6 (2014) 
hombre primitivo intenta siempre penetrar en un centro desde donde poder orientarse y entablar una comunicación con lo sagrado. Eliade ha visto correctamente en esta tendencia la nostalgia del paraiso del ser humano. «[El simbolismo del Centro] pone de relieve determinada situación humana que podríamos llamar nostalgia del paraíso. Con esto significamos el deseo de hallarse siempre y sin esfuerzo en el Centro del Mundo, en el corazón de la realidad, y, en resumen el deseo de superar de un modo natural la condición humana, y de recobrar la condición divina» ${ }^{11}$. El paraiso es el modelo según el cual el hombre primitivo hace habitable la tierra. Ahora bien, el paraiso es la negación del tiempo. Para el hombre primitivo, morar la tierra significa demorarse, dilatar el tiempo, recrearse en presencia de lo sagrado.

\section{LA REPETICIÓN}

El hombre primitivo no solo repite la cosmogonía sino en general cualquier acto ejemplar revelado por los dioses. "Todos los actos importantes han sido revelados ab origine por los dioses o héroes. Los hombres no hacen sino repetir infinitamente estos gestos ejemplares y paradigmáticos." 12 Las bacantes imitaban en su ritos orgiásticos a Dionisos, igual que en los ritos órficos se imitaban las hazañas de Orfeo. Todas las ceremonias importantes de las sociedades arcaicas repiten alguna hazaña de un dios. Los matrimonios repiten la hierogamia sagrada en que el dios se unía a la diosa "En Grecia los ritos matrimoniales imitaban a Zeus que se unió secretamente con Hera." 13 También las actividades cotidianas (la caza, la pesca, la agricultura...) repetían lo que ocurrió en el tiempo sagrado de los dioses. "La ceremonia hindú de la consagración de un rey, el rajasuya, no es más que la reproducción terrestre de la antigua consagración que Varuna, el primer soberano, hizo en su provecho." ${ }^{14}$ En último término podría decirse que lo que confiere realidad a un acto es su repetición de un arquetipo. La realidad se obtiene por repetición de lo sagrado.

11 M. ELIADE (1955) Imágenes y simbolos. Taurus. 1992. p.58.

12 M. ELIADE (1951) El mito del eterno retorno. Madrid: Alianza Editorial. 2011. p. 47.

13 Íbid., p.37.

14 Íbid., p. 44.

Claridades. Revista de Filosofía, 6 (2014) 
Nosotros como filósofos podemos reconocer en Platón al filósofo más representativo de la mentalidad arcaica. En realidad la filosofía de Platón no es más que la formulación metafísica del modo de pensar primitivo. El pensamiento de los primeros filósofos no es, como suele decirse, una superación del mito, sino más bien su traducción a conceptos. Los conceptos universales adquieren el carácter sagrado que antes tenían los mitos. Pero además hay que decir que en la filosofía de Platón se encuentran las primeras huellas del olvido de lo sagrado en el pensamiento moderno. Este carácter sagrado de los conceptos se mantendrá hasta en el positivismo. Así, en un mundo en el que se ha olvidado hace ya mucho a los dioses, se mantienen todavía las estructuras fijas de la ontología arcaica por las que todavía se siente un temor reverencial.

Tal vez el elemento más característico de la ontología arcaica que se mantiene en la filosofía de Platón sea la abolición del tiempo por repetición o participación de lo sagrado. El arquetipo abre el tiempo mítico al repetirse. El hombre primitivo busca sustraerse al efecto disolvente, corruptor del devenir para permanecer en la cercanía del ser. Este esfuerzo constante es el esfuerzo de la repetición que el hombre primitivo no puede dejar de realizar para dotar de realidad y sentido a su mundo. Pero no solo esto, el hombre primitivo al ejercitarse en la repetición adquiere el valor suficiente para enfrentarse al mundo. Entre las tribus de Nueva Guinea "cuando un capitán se hace a la mar, personifica al héroe mítico Aori. Lleva el traje que Aori vestía, según el mito; como él tiene la cara ennegrecida, y en los cabellos un love semejante al que Aori quitó de la cabeza de Iviri... Un pescador me dice que cuando iba a capturar peces (con su arco) se consideraba el propio Kivavia." 15 Identificándose con Aiori, el capitán del navío se arma de valor parara realizar su viaje, pero además, adquiere el poder necesario para realizarlo con éxito. No es una cuestión solamente de valor o de ánimo, sino también de poder. La repetición de las hazañas del héroe primitivo volvia capaces a los hombres para realizar hazañas de las que jamás se hubieran considerado capaces de no ser por el mito. Precisamente porque para las sociedades arcaicas no existe una separación neta entre poder y ser, la repetición es también aquello que dota de poder a los individuos.

Por lo tanto, el hombre se transforma en el héroe mítico mediante la repetición. Pero también a ocurre que la memoria colectiva transforma

15 Íbid., p. 47. 
en héroes míticos a los personajes históricos. Es lo que ocurrió con personajes como Alejandro Magno o el Cid. En el caso de la epopeya yugoslava, Marko Krajlevic fue un guerrero de la segunda mitad del siglo XIV que murió en 1394. De su vida real poco se sabe. La memoria popular anuló completamente su biografía real para construir un mito. Su madre fue una Vila, igual que su esposa. Las Vila eran hadas que curaban a los héroes heridos, los podían resucitar o podían advertirles de peligros inminentes. Marko combate con un dragón alado de tres cabezas y lo mata. Y por último se ve obligado a enfrentarse a su hermano Andrija y matarlo. De esta manera, la vida de un personaje real es reconstruida según normas míticas donde se confunde lo real con lo imaginario. La memoria colectiva ha transformado lo real en nuevo mito. Muy ilustrativo en esta dirección es el caso que expone el folklorista Constantin Brailiu. ${ }^{16}$ En un pueblo de Maramuresh hay una balada que cuenta como un joven prometido fue hechizado por un hada que, por celos, lo había tirado por una montaña. Cuando la joven con la que estaba prometida vio su cuerpo muerto entonó el cántico fúnebre que dio a conocer el mito. Brailiu averiguó que en realidad, se trataba de una historia que había ocurrido hace cuarenta años. Conoció a la protagonista que le relató los hechos a los que se refiere el mito. En realidad su novio mientras un día caminaba por la montaña simplemente tropezó, se cayó y murió. Así pues, en un corto espacio de tiempo, el acontecimiento histórico se transformó en suceso mítico. Pero lo realmente interesante ocurrió cuando Brailiu le contó a los residentes del lugar la versión auténtica de la historia. Ellos reaccionaron diciendo que la mujer del mito había enloquecido y en su dolor se contaba a sí misma una ficción que nada tenía que ver con la verdadera historia. El mito era lo que contaba la verdad, mientras que los hechos reales eran una simple mentira.

La interesantísima historia de Brailiu ilustra como la acción corrosiva de la mitificación afecta a la memoria histórica. "Podría decirse que la memoria popular restituye al personaje histórico de los tiempos modernos su significación de imitador del arquetipo y de reproductor de las acciones arquetípicas." ${ }^{17}$ Esta restitución característica de la memoria popular es ya la repetición. Llevaría tiempo demostrar que esta característica de la memoria popular está en toda forma de memoria. Contra más

16 Íbid., p. 61.

17 Íbid., p. 60.

Claridades. Revista de Filosofía, 6 (2014) 
lejano sea el recuerdo, tanto más afectada por lo imaginario está la memoria. Por ello, el pensamiento que recuerda los orígenes se ve transportado a un tiempo (lo que Eliade llama illo tempore) que no necesariamente coincide con los acontecimientos reales. El recordar se mantiene en un tiempo propio, extraño por completo a la linea de sucesos reales constatables, que se refiere a la repetición de acontecimientos desencadenados en un origen.

\section{EL TIEMPO COMO REPETICIÓN}

En todas las sociedades primitivas y algunas históricas existe una concepción del tiempo como repetición de ciclos. Al final de cada ciclo y al comienzo del nuevo, dependiendo de cada sociedad, se realizan una serie de rituales de finalización y de recomienzo. Estos rituales aseguran la regeneración periódica del tiempo.

La estructura de las ceremonias del final de un ciclo y comienzo del siguiente se componen en general de dos fases: la regresión al caos y la creación de un nuevo mundo por el dios. Durante la regresión al caos se celebran las correspondientes saturnales en donde el rey se convierte en mendigo, el mendigo en rey, se abole toda jerarquía, se invierten los roles y se permiten toda clase de licencias sexuales. En algunos casos se celebran orgías, en otros los muertos invaden el mundo de los vivos. Durante esta fase se celebra la disolución universal de toda forma, su retorno al caos. "En Japón, así como entre los germanos (y otros pueblos indoeuropeos), la última noche del año está señalada por la aparición de los animales funerarios (caballo, etcétera) de las diosas y los dioses ctónicofunerarios; es entonces cuando se verifican los desfiles de enmascarados de las sociedades secretas de los hombres, cuando los muertos visitan a los vivos y cuando se celebran las iniciaciones. ${ }^{" 18}$ La siguiente fase es la creación del mundo por el dios. Así, por ejemplo, en la ceremonia del Nuevo Año babilónico llamada akitu, se recitaba varias veces el Enuma elish, el poema de la creación en el templo de Marduk. El poema reactualizaba la victoria de Marduk contra el monstruo Tiamat que creó el cosmos. Unos figurantes escenificaban el combate del dios en el templo. Esta puesta en escena de la lucha primordial no era una simple imitación o una interpretación teatral de lo que se supone ocurrió en el tiempo mítico. Los figurantes se identificaban plenamente con el dios o el mons-

18 Íbid., p. 86.

Claridades. Revista de Filosofía, 6 (2014) 
truo, la victoria de Marduk ocurría en ese preciso momento. La ceremonia, en cierto modo, crea el año venidero.

Este simbolismo de la regeneración periódica del tiempo está extremadamente difundido. Encuentra sus fundamentos la mística lunar de las sociedades preagrarias «Aquí bastará que recordemos que si la luna sirve para medir el tiempo (en las lenguas indoeuropeas la mayor parte de los términos que designan los meses y la luna derivan de la raíz me-, que ha dado en latín tanto mensis como metior, "medir") si sus fases revelan mucho antes que el año solar y de manera mucho más correcta- una unidad de tiempo (el mes) a la par revela el eterno retorno.» ${ }^{19} \mathrm{El}$ tiempo de las sociedades se estructura en ciclos por analogía con los ciclos de la luna. Al final de cada ciclo, el mundo se encuentra desgastado, corrompido, agotado. Es preciso renovarlo por completo mediante la repetición de la cosmogonía. El mundo o la vida no puede ser reparado, sino solo recreado. El tiempo histórico tiene un efecto disolvente: corrompe y aleja al hombre de lo sagrado. Repetir la ceremonia de creación tiene como efecto restaurar el mundo en toda su plenitud Esta misma idea sirve también de base a las ceremonias de purificación como la expulsión de los males y la confesión de los pecados. Los pecados y los males en general, como las enfermedades, son un resultado de la caída del hombre en el tiempo histórico. Al confesar los pecados el ser humano se libera de su propia historia personal individual para reintegrarse en la plenitud objetiva de lo sagrado. Lo subjetivo, lo personal, lo histórico carecen de valor alguno para el hombre primitivo. La confesión o la disolución en el caos seguida de la repetición de la cosmogonía tiene el efecto de liberar de lo histórico o de lo personal.

El hombre primitivo está caracterizado por una voluntad de desvalorizar el tiempo. Eliade llega a afirmar que "[para el hombre primitivo] si no se le concede ninguna atención, el tiempo no existe; además cuando éste se hace perceptible (a causa de los pecados del hombre, o cuando éste se aleja del arquetipo y cae en la duración), el tiempo puede ser anulado." ${ }^{20}$ Esto quiere decir que el hombre primitivo vive en un eterno presente y todo su esfuerzo va dirigido a no alejarse de él. Todos sus rituales de repetición tienen esta finalidad. Repite porque no puede ignorar el tiempo y necesita mantenerse en la cercanía de lo sagrado. Repite

19 Íbid., p. 103.

20 Íbid., p.102.

Claridades. Revista de Filosofía, 6 (2014) 
para anular el tiempo, pero en cierto modo, al repetir crea el tiempo. Lo crea desde el momento en que la repetición configura todo un calendario. La duración del año como comienzo y fin de la cosmogonía, el mes como unidad de medida que es herencia de una arcaica mística lunar, la asignación de festividades sagradas para cada día, toda la conducta del hombre primitivo en relación al tiempo se halla determinada por la repetición de lo sagrado. Para la ontología arcaica el tiempo es repetición.

\section{LA SUPERACIÓN DEL ETERNO RETORNO POR EL CRISTIANISMO Y EL JUDAÍSMO}

El mito del eterno retorno o el tiempo entendido como repetición forma parte de la cosmovisión del hombre primitivo. No obstante, el pueblo judío ha pensado de otra manera el problema del tiempo. Los hebreos fueron los primeros en valorizar la historia. El tiempo para ellos no consiste simplemente en retornar una y otra vez a lo sagrado que se manifiesta, sino que se trata de un tiempo lineal. Dios creó el mundo en un tiempo primordial y lo destruirá en un futuro. El pueblo judío soporta la historia porque algún día terminará, pero además, porque es una teofanía. Dios interviene en la historia para corregirla o para orientarla. Cada situación en la historia es una prueba de Dios para salvar a los judíos. El judaismo no solamente revaloriza lo histórico sino también lo personal. Dios se revela como "persona" a Moisés en el Sinaí. Por ello, la historia constituye un "terrible diálogo" de Dios con el hombre. "Dios se revela como personal, como una existencia "totalmente distinta" que ordena, gratifica y pide, sin ninguna justificación racional (es decir, general y previsible) y para quien todo es posible" 21 . Dios interpela al pueblo judío cada vez que se aleja de Él para adorar a Baal o a Astarté. Cada catástrofe o cada derrota militar se justifican porque son una intervención de Dios en la historia. Esta es la manera que tiene el pueblo judío de aceptar el sufrimiento, darle sentido. A diferencia del hombre moderno, el hombre primitivo no puede pensar la idea de un sufrimiento absurdo sino que todo sufrimiento tiene siempre un sentido. El sufrimiento es de alguna manera lo que le lleva de vuelta a lo sagrado. Muestra una situación de extravío con respecto a una norma. Es importante subrayar el hecho de

21 Íbid., p. 129.

Claridades. Revista de Filosofía, 6 (2014) 
que el pueblo judío pudo sobrevivir a todas las calamidades que padeció precisamente porque las consideró como teofanías. ${ }^{22}$

En el caso del cristianismo Dios se encarnó en el tiempo para toda la eternidad. Esto confiere un sentido único a la historia. Ésta sigue siendo lineal pero ahora está determinada por la paradoja de la encarnación: que lo eterno se hizo temporal para salvar a los hombres. La escatología cristiana de la historia fue elaborada por san Agustín en su Civitate Dei. Esta concepción lineal se mantuvo durante toda el medievo combiándose con la concepción del tiempo cíclico de tiempos más arcaicos que sobrevivía en la astrología. Pensadores como San Alberto Magno o Santo Tomás mantuvieron la creencia en el tiempo cíclico de la astrología. En el siglo XII, Joachim de Fiore fue el primero que sentó las bases del progreso lineal en la historia en su Evangelio Eterno. La historia se dividiría en tres épocas: la del Padre, la del Hijo y la del Espíritu Santo. Solamente en esta última encuentra el ser humano la libertad absoluta. Pero será Hegel en el siglo XIX quien de la formulación filosófica más completa a la concepción lineal de la historia.

\section{EL OLVIDO DE LO SAGRADO}

La modernidad está dominada toda ella por un progresivo olvido del tiempo sagrado. Ya en el siglo XIX Hegel afirma la pura inmanencia de un tiempo histórico que no necesita para nada de un modelo trascendente que lo justifique. Los acontecimientos históricos son necesarios solamente porque ocurrieron de ese modo y no de otro. Todas las catástrofes se justifican por una necesidad histórica para la que nada cuentan los individuos concretos. El historicismo, heredero de la perspectiva hegeliana, afirma la relatividad de cada época histórica y la imposibilidad absoluta de salirse de ella. El hombre es un ser histórico que está siempre en una situación que le impide acceder a un conocimiento absoluto. Para los existencialistas el absurdo del mundo o la nada de la existencia se presenta como la última realidad. Haga lo que haga el ser humano no podrá jamás trascenderla. El hombre está solo en el mundo, es libre y responsable de sí mismo ante los demás. Pero para el existencialismo ninguna decisión es mejor que la otra, todas son iguales. «En el fondo, emboraracharse en la soledad es lo mismo que conducir a los pueblos. Si

22 Ningún pueblo primitivo hubiera podido sobrevivir de no ser por su relación con lo sagrado

Claridades. Revista de Filosofía, 6 (2014) 
una de estas actividades es superior a la otra no es a causa de su objetivo real, sino a causa de la conciencia que posee de su objetivo ideal; y en este sentido, el quietismo del borracho solitario es superior a la vana agitación del conductor de los pueblos.» ${ }^{23}$ Con el existencialismo se lleva a su máxima expresión el olvido de lo sagrado que ya diagnosticó Nietzsche en la Gaya Ciencia.

Lo sagrado era para el hombre primitivo tanto el planteamiento de una grave crisis existencial como su solución. Lo sagrado ha ayudado al hombre a afrontar las duras condiciones a las que se ha visto arrojado a lo largo de la historia. Queremos subrayar con Eliade el carácter efectivo que tuvieron los ritos en las sociedades arcaicas. El ser humano se sirvió de ellos durante milenios para plantear y resolver situaciones prácticas y poder con ello superar los problemas que aquejaban su existencia. A través de los mitos, el hombre primitivo adquiere el dominio simbólico necesario para elaborar las experiencias traumáticas.

No se trata aquí de valorar el olvido de los dioses por el pensar occidental y la afirmación del tiempo profano. Sin embargo, Eliade realiza la siguiente observación: «el historicismo fue creado y profesado ante todo por pensadores que pertenecían a naciones para las cuales la historia jamás fue un terror continuo. Esos pensadores quizá hubieran adoptado otra perspectiva si hubiesen pertenecido a naciones señaladas por la fatalidad de la historia. En todo caso, nos gustaría saber si la teoría según la cual todo lo que sucede está bien justamente porque sucedió habría podido ser abrazada alegremente por los pensadores de los países bálticos, de los Balcanes, o de las colonias.. ${ }^{24}$

Por último, podríamos preguntarnos qué ha ocurrido en las sociedades modernas con todo el simbolismo religioso con que la humanidad expresó su experiencia de lo sagrado. Sin duda, dichos símbolos están presentes en la historia del arte o de la literatura y el ser humano se ha servido de ellos inconscientemente para expresar sus vivencias. De alguna manera en la actualidad tales símbolos sobreviven. Esto ha sido puesto de manifiesto por los trabajos del psiquiatra suizo Carl Gustav Jung (1875-1961) quien interpretó los fenómenos oníricos de una forma completamente distinta a como hiciera Freud. Jung descubrió que el material onírico que aportaban los pacientes que estaban atravesando una crisis muy grave podía interpretarse como expresión de los arquetipos de la

23 J.P. SARTRE (1943) El ser y la nada. Buenos Aires: Losada. 2005.

24 M. ELIADE. El mito, op. cit.,p.174.

Claridades. Revista de Filosofía, 6 (2014) 
mitología. La mayoría de pacientes que trataba Jung eran psicóticos, a diferencia de los neuróticos tratados por Freud. Jung distinguía entre un inconsciente personal y uno colectivo. Éste último se manifestaría en las psicosis, de la misma forma que en las sociedades primitivas, ocurre una hierofanía tras una grave crisis. De esta manera Jung ha conseguido encontrar una relación entre la psicopatología, la etnología y la mitología. El inconsciente colectivo sería el denominador común de estos tres campos de estudio. Eliade explica esta situación de la siguiente manera: «en la medida en que el inconsciente es el "precipitado" de las innumerables situaciones límite, no puede dejar de parecerse a un universo religioso. Por cuanto la religión es la salida ejemplar de toda crisis existencial... la experiencia religiosa es a la vez crisis total de la existencia y solución ejemplar de esa crisis.» ${ }^{25}$

\section{CONCLUSIÓN}

Mircea Eliade compara la crisis de Occidente con la leyenda de Parsifal y el Rey Pecador. Cuenta esta leyenda que en una región desértica y yerma había un castillo con un rey enfermo. Éste se lamentaba de sus desgracias y se preguntaba si algún día dejarían de afligirle. Un día llegó un caballero de nombre Parsifal y comenzó a preguntar a todos por las causas del mal que había caído sobre aquel castillo. En el castillo todos los ignoraban y ya amenazaba el rey con expulsarlo cuando éste de repente preguntó: “¿dónde está el Grial?”. En ese preciso momento, la tierra reverdeció y se volvió fértil, el rey sanó, se volvió fuerte y sabio. Lo que el mito enseña es la importancia de la pregunta correcta para sanar el mal. En este ejercicio de volver a formular la pregunta correcta es donde se encuentra la salvación. Más que soluciones concretas a problemas prácticos, nuestro tiempo exige un mayor esfuerzo al pensar: el de formular la pregunta correcta. Este es justamente el ejercicio de la filosofía. Solamente preguntando de nuevo y preguntando mejor se vuelve a encontrar el camino.

\section{REFERENCIAS BIBLIOGRÁFICAS}

J.P. SARTRE (1943) El sery la nada. Buenos Aires: Losada. 2005.

25 M. ELIADE. Mitos, op. cit. p. XVI. La cursiva es mía.

Claridades. Revista de Filosofía, 6 (2014) 
M. ELIADE (1951) El mito del eterno retorno. Madrid: Alianza Editorial. 2011.

M. ELIADE (1957) Lo sagrado y lo profano. Barcelona: Editorial Labor.1994.

M. ELIADE (1963) Mito y realidad. Barcelona: Editorial Labor. 1994.

M. ELIADE (1964) Tratado de historia de las religiones. Madrid: Ediciones Cristiandad. 1974.

M. ELIADE (1992). Imágenes y simbolos. Taurus.

M. ELIADE. (1955) Mitos, sueños y misterios. Madrid: Grupo Libro 88.

LUCAS RisOTO DE MESA es traductor de inglés y alemán, licenciado en filosofía, y colaborador en el grupo diáspora traducciones.

Lineas de investigación:

Psicoanálisis y hermenéutica.

Publicaciones recientes:

Los sueños como expresión de la verdad. Una introducción a la psicología fenomenológica, en Claridades 3 (2011)

El caso de Franz Antón Mesmer (1734-1815), en Claridades 4 (2012)

Dirección electrónica: lcrdemesa@googlemail.com

Claridades. Revista de Filosofía, 6 (2014) 